\title{
Legal consensus eludes Europe
}

$\mathrm{A}$

recent ruling by Britain's High Court on assisted suicide and a television documentary showing a man taking his own life has reopened debate on the subject in the United Kingdom and other European countries.

In October 2008, Debbie Purdy, who suffers from multiple sclerosis, lost a legal bid to clarify the law on assisted suicide. A 1961 law makes it an offence to "aid, abet, counsel or procure" a suicide or suicide attempt in England and Wales. Purdy indicated that at some future date she might travel to Switzerland, where assisted suicide is legal, but wanted assurances that her husband would not be prosecuted if he accompanied her. Purdy's lawyers obtained a judicial review of the 1961 law, arguing that the lack of clarification violated her human rights. The High Court judges, while expressing sympathy for Purdy, ruled that her rights had not been infringed upon and that existing legal guidelines were sufficient.

Purdy's case is not the first time the issue has been raised in British courts. In 2001, Diane Pretty, who suffered from amyotrophic lateral sclerosis, unsuccessfully sought immunity for her husband to help her end her life in the UK. She took her case to the Human Rights Court in Strasbourg, France, which ruled that her rights had not been infringed upon and that the "right to life" did not confer a "right to die." Pretty died on May 12, 2002, barely a month after the human rights court made its ruling.

At least 100 British citizens have ended their lives at the Dignitas Clinic in Switzerland, which allows assisted suicide, and until now none of their relatives or friends have been charged. But British police investigated the case of Daniel James, a 23-year-old rugby player paralyzed in a training accident, who died at the clinic in September 2008. His parents, who accompanied him to Switzerland, were questioned by authorities, who later said that while there were sufficient grounds to charge the couple, a prosecution would not be "in the public interest."

On Dec. 10, 2008, Britain's Sky TV aired a documentary on the death of

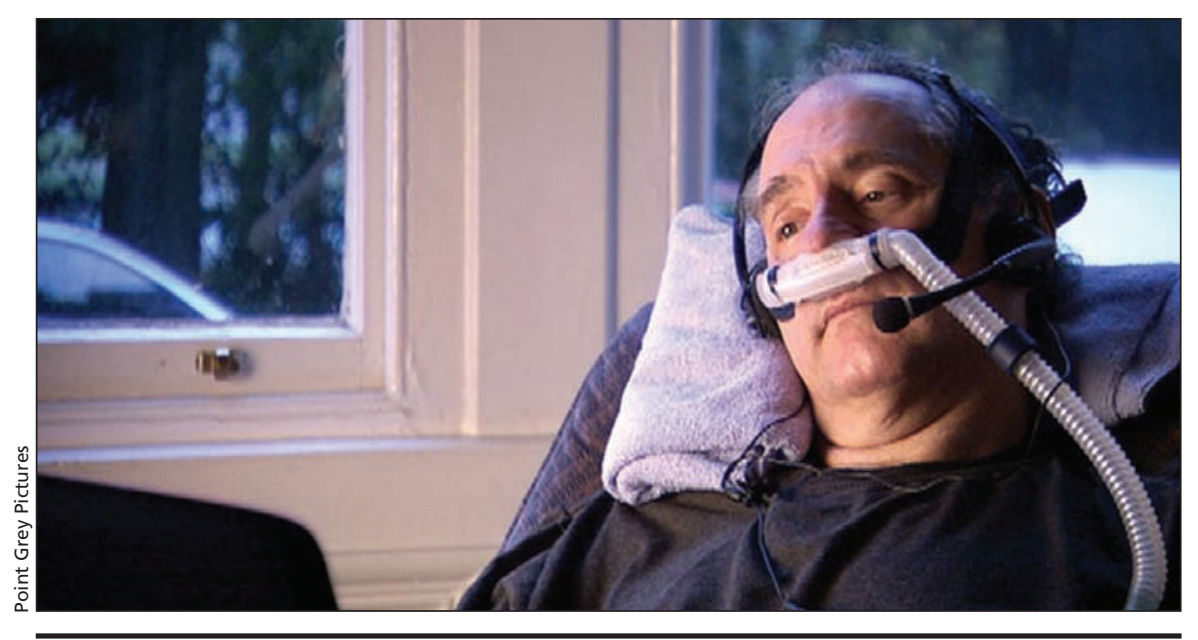

The assisted death of Craig Ewert, a 59-year-old American academic with amyotrophic lateral sclerosis, took place at Switzerland's Dignitas Clinic in September 2006 and was later broadcast on British television.

Craig Ewert, a 59-year-old with amyotrophic lateral sclerosis, at the Dignitas Clinic in September 2006. The film showed Ewert, an American academic residing in the UK, drinking a mixture of sedatives and turning off his ventilator with his teeth. A spokeswoman for the program called it "an informative, articulate and educated insight into the decisions some people have to make." But antisuicide campaigners such as Dr. Peter Saunders of the group Care Not Killing attacked the program as "a cynical attempt to boost television ratings."

Dignitas was founded in 1998 by Ludwig Minelli, a Swiss lawyer, who runs it as a nonprofit. Switzerland's laws suggest that those taking part in assisted suicide — providing patients with means to end their lives — will not be prosecuted unless they acted in self-interest. But there is no legal consensus among European countries.

In 2002, the Netherlands became the first country in the world to pass an euthanasia law, which strictly limits the practice to patients with incurable conditions. The patient must be fully cognizant and receive a second medical opinion, and each case is reviewed afterward by a committee. Similar laws exist in neighbouring Luxembourg and Belgium, where at least 5 non-Belgians have gone to end their lives, taking advantage of a European Union provision allowing patients to seek care in other member countries if it is unavailable at home.

Earlier this year a Belgian doctor invited Chantal Sebire, a French national suffering from a painful and inoperable esthesioneuroblastoma, to end her life at his hospital. A French court had rejected her request for medical help to die, arguing that the country's 2005 "end of life" law allowing the withdrawal of medical treatment did not allow assisted suicide. Sebire was later found dead in her home in Dijon, an apparent suicide, prompting renewed calls for a change in the law.

German law is unclear, with no specific ban on assisted suicide, but physicians must not get involved lest they violate their legal obligation to save lives. Last summer, an assisted suicide campaigner, Roger Kusch, caused an outcry when he held a press conference to describe the case of a 79-year-old woman who was neither sick nor dying but had chosen to die rather than move into a nursing home. German officials condemned Kusch's actions.

The Czech Republic's senate recently rejected a bill to legalize assisted suicide. Spain's health ministry has proposed changes in the law to prevent "needless suffering" but faces strong opposition from conservatives as well as socialists. Italy and Sweden do not allow assisted suicide but recognize the right of a patient to refuse medical treatment. In practice, however, patients' wishes are not always respected. 
Last year, Piergiorgio Welby, who suffered from advanced muscular dystrophy, died after going on a hunger strike when police prevented his doctor from switching off his respirator. A judge rejected Welby's petition, saying that while he had a constitutional right to determine his medical treatment, Italian doctors must not carry out treatments "aimed at causing death." - Mary Helen Spooner, London, England

DOI:10.1503/cmaj.081965

\section{Direct v. indirect euthanasia}

Direct active euthanasia involves specific actions to cause a patient's death, such as administering an overdose of drugs. This practice is illegal in most countries, including Switzerland. Indirect active euthanasia involves giving the patient a palliative, such as a strong sedative, which could lead to death. This is allowed in Switzerland, the Netherlands, Luxembourg and Belgium. Passive euthanasia is defined as withdrawing life support or other medical treatment, often at the patient's request, and is legal in many countries. Assisted suicide is defined as providing patients with the means to end their own lives, but not directly administered by doctors.

\section{FOR THE RECORD}

\section{Serving up progress}

$\mathrm{T}$ The United States is making significant progress in its goal to better protect its food supply, according to a report from the US Food and Drug Administration (www.fda .gov/oc/initiatives/advance/food/progress report1108.html).

The report, which evaluates progress in implementing the Food Protection Plan, notes successful measures in 2008 included the irradiation of lettuce to reduce E. coli; genetic analysis of new Salmonella strains; improved methods of detecting melamine; rapid detection of $C$. botulinum, E. coli and Salmonella in food-processing plants; and the signing of an agreement between 6 states to form a rapid response team to "develop, implement, exercise and integrate response" to foodborne illness.

Food quality and safety standards in Canada, enforced by the Canadian Food Inspection Agency, differ substantially from US regulations. For example, food inspectors visit and assess meat processing plants 3 times a week in Canada, as opposed to daily in the US.

"Canadian standards are not as prescriptive as the US for plant evaluations, and therefore results in less frequent visitations," says Marc Richard, a Canadian Food Inspection Agency spokesman.

While the United States is highlighting its success in food protection, the memory of the recent listeriosis outbreak in Canada - and its death toll of 20 - is fresh in the minds of Canadians (CMAJ 2008;179[9]:877-9). A probe into the out-

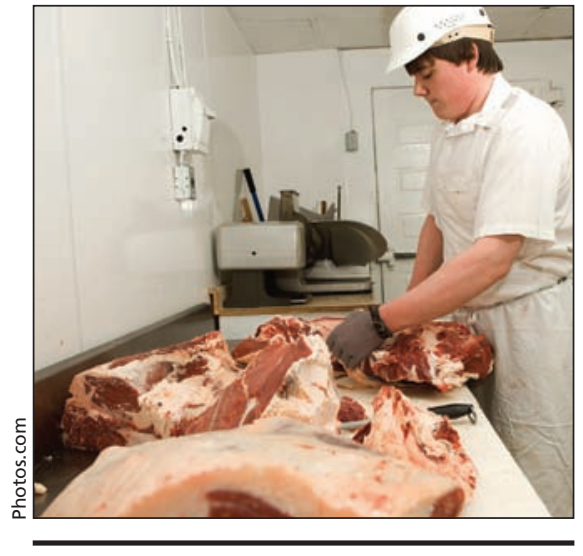

The United States is making significant progress in protecting its food supply, a recent report indicates.

break, commissioned by Prime Minister Stephen Harper, is due early in 2008 . David Manly, Ottawa, Ont.

\section{Healthy competition}

$\mathrm{P}$ ublic drug plans, businesses and individuals could enjoy annual savings of up to $\$ 800$ million if there were more competition in the generic drug market, according to a federal Competition Bureau report.

The bulk of potential savings - up to $\$ 600$ million - would be reaped by businesses, private drug plans and individuals who pay out of pocket. Public plans could also cut costs by about $\$ 200$ million annually. Potential savings will increase as more drugs come off patent, according to the report, which outlines strategies for increasing competition.

An earlier report from the bureau found that although there is generic drug competition in Canada at the pharmacy level, savings from rebates and allowances were not being passed on to customers. - Ann Silversides, CMAJ

\section{Slight decrease in HIV and AIDS rates}

$\mathrm{T}$ he number of new positive HIV test reports dropped 5\% in 2007 compared to 2006, according to the Public Health Agency of Canada's year-end booklet, HIV and AIDS in Canada.

The exact cause of the 5\% decrease is not clear, stated agency spokesman Michael Tansey in an email. Small fluctuations can be caused by a number of factors, he noted, "such as an increase or decrease in reporting, an increase or decrease in HIV testing, and an increase or decrease in underlying infection rates."

Due to changes in data collection procedures, immigration rules and testing policies, fewer positive cases were reported among women and people from HIV-endemic countries.

Of the 2432 new cases, $41.3 \%$ were among men who have sex with men. Increased infection rates were observed among young women practising unsafe sex and Aboriginal intravenous drug users. Since 1985, almost 65000 cases of HIV/AIDS have been documented by the Agency. - Lesley Ananny, Ottawa, Ont.

DOI:10.1503/cmaj.082067 